\title{
Possible Improvement of Radiotherapy Effectiveness Using a Combination of Islamic Fasting and Short-Term Cold Hydrotherapy
}

\author{
Jaafar EL Bakkali ${ }^{1,2 *}$, Khalid Andaloussi Saghir ${ }^{2}$, Hamid Mansouri ${ }^{2}$ and Abderrahim Doudouh ${ }^{1}$ \\ ${ }^{1}$ Department of Nuclear Medicine, Military Hospital Mohammed V, Morocco \\ ${ }^{2}$ Department of Radiotherapy, Military Hospital Mohammed V, Morocco
}

Submission: October 23, 2017; Published: October 31, 2017

*Corresponding author: Jaafar EL Bakkali, Department of Nuclear Medicine \& Radiotherapy, Military Hospital Mohammed V, Rabat, Morocco, Email: bahmedj@gmail.com

\begin{abstract}
A hypothesis is postulated that attaching intermittent fasting and cold short-term hydrotherapy at $18^{\circ} \mathrm{C}$ to the radiotherapy treatment can upraise its effectiveness. It was elaborated based on the well-known impacts of the two naturopathic arms on stimulating both metabolic and antioxidant systems against both cancer developing and damages provoked by ionizing radiations on normal tissues. This hypothesis can be easy tested clinically on patients suffering from cancer diseases and doesn't seem to generate potential common or rare side effects on patients which are subject of radiotherapy treatment.
\end{abstract}

Keywords: Radiotherapy; Hydrotherapy; Islamic fasting; Cancer; Cold exposure; Naturopathic

\section{Background}

The radiotherapy constitutes beside surgery and chemotherapy the three major cancer therapeutic arms, it is utilized for treating patient with cancer diseases by mean of ionizing radiations which have heavily biological effects on both cancerous and normal cells, indistinguishably. Thus, the employ of ionizing radiations for treating of cancer diseases absolutely conduct to exposing the surrounding normal tissues. Ionizing radiations used in radiotherapy can surely induce potential damage on all kind of human tissues without exception. Indepthly, the propagated damage manifested on the DNA infliction of cells which may occur either directly or either indirectly. Directly means, that the DNA strand of cells breaks as response to direct energy deposition of ejected electrons, whereas indirectly means that the ejected electrons react with water molecules, as result the water molecules will be dissociated in response to the ionizing radiations, this phenomena is knows as water radiolysis, consequently a powerful free radicals with highest reactivity will be created namely hydroxyl $(\mathrm{OH}$.) and hydrogen (H.) radicals, these radicals are themselves chemically reactive, and in turn will be recombined to produce a series of highly reactive combinations known as reactive oxygen species (ROS) such as superoxide $\left(\bullet \mathrm{O}^{-2}\right)$ and hydrogen peroxide $\left(\mathrm{H}_{2} \mathrm{O} 2\right)$.
These ROS will induce a potential oxidative damage on biological macromolecules such proteins, lipids and DNA, causing fatal lesions in cell that contribute to carcinogenesis. Fortunately, the human body has a defense system of antioxidants (superoxide dismutase and gluthatione) delivering some proteins to prevent oxidative damage generated by reactive oxygen species.

Go more in depth, cellular components within cells of human tissues use oxygen in combination with other molecules to generate energy needed to run a lot of biochemical processes. During the executing of energy generation process, the nutrients supplied by the food are burned with oxygen to release energy, reactive oxygen species are created which play an important role in cell signaling provided that they remain in friendly concentrations. However, when they became much concentrated, as may occur as a result of exposing to ionizing radiations, they may enter in direct contact with cellular components such as DNA, proteins, and lipids, by themselves, they become particularly toxic and they can provoke the risk of second cancer knows as radiation-induced cancer.

Against these hurtful side effects of radiotherapy on health tissues, the radiotherapy must be coupled with others therapeutic arms in aim to upraise its effectiveness. After a 
depth review of a large number of scientific papers concerning the subject of relationship between cancer and natural medicine therapeutic arms, we have found that the intermittent fasting and cold hydrotherapy may be the preferential choices. Despite biological effects induced by the two above therapeutic arms that are almost well identified, the invoked mechanisms are not studied well nor well-understood, further researches must be carried out in aim to decode these mechanisms.

To the best of our knowledge this is the first hypothesis that suggest to investigate clinically, both the Islamic fasting and the short-term cold hydrotherapy for elevating the effectiveness of radiotherapy treatment. The idea of using intermittent fasting like Ramadan was inspired from its clinical application on cancer chemotherapy treatment, which has been studied in some papers [1-5]. We present a detailed impact of both intermittent fasting and cold hydrotherapy on skipping development of cancer cells and on protecting surrounding health cells from a scientific point of view.

\section{Hypothesis}

Attaching Ramadan fasting and Cold hydrotherapy to the radiotherapy treatment might protects healthy cells against side effects of radiotherapy treatment and makes cancerous and precancerous cells more vulnerable to it, consequently it may increase its effectiveness. This hypothesis suggests in the one hand that patients need to get a short-term cold exposure at $18{ }^{\circ} \mathrm{C}$ delivered by a shower sprinkler at average flow rate of 3 gallons per minute (gpm), the exposure time need to be five minute just after and before each radiotherapy treatment sitting. In the other hand the treatment sittings need to be performed just after two hours before sunset where the glucose level will be at its lowest value.

\section{Evaluation of the Hypothesis}

The present hypothesis is supported by a set of scientificbased evidences retrieved from a number of scientific papers. Indeed, starting with Ramadan fasting arm, it seems to sensitize tumor cells and increase the outcome of radiation therapy [6] and it may induce brutal physiological changes that may conduct to chromatin remodeling [7] and metabolic pathways reprogramming $[8,9]$. In particular, Ramadan fasting may considered as anticancer therapy and it has a lot of benefits against others kind of intermittent fasting [1]. Leiper point out in his paper [10] that no negative effects on health of fluid restriction may appears during fasting in Ramadan. In their paper [9], Longo \& Mattson [9] claim that fasting has the potential for applications in both cancer prevention and treatment. In other papers [11,12], the Ramadan fasting seems to elevate the level of antioxidant enzyme named glutathione. Indepthly and in more detail, Ramadan fasting has potential positive effects on two kind of cells, namely normal and cancerous cells. For cancerous cells it may decrease levels and down-regulate activity of three components who contribute to development of cancer diseases: a) The insulin-like growth factor-1 (IGF-1), this hormone contributes to the growth of cancerous tumors [13].

b) Insulin which enhances metabolic capacities of cancer cells [14].

c) Glucose which might fuel the growth of cancer. Ramadan fasting has also a positive effects on the immune system, particularly on natural killer cells and on the antioxidant system participating the control of the growth of cancerous cells [15]. Regarding normal cells, Ramadan fasting might increase levels of Insulin-like growth factor-binding protein (GFBP1) which inhibits cancer cell invasion [16] as well as ketone bodies which induce metabolic pathways reprogramming [17], this may conduct to establish a protective environment for DNA cells of health tissues thereby triggering normal cells to enter into a protective mode, then may reduce oxidative damage and the occurrence of carcinogenesis, and may also establish an hell environment for precancerous and cancerous cells by optimizing energy metabolism. Explicating more, during, Ramadan fasting the level of glucose in the blood being lower, the ketogenesis (production of ketone bodies from fatty tissues) takes place, and the body uses ketone bodies as fuel instead of glucose. The ketogenesis contributes to reprogramming energy metabolism and changing the cellular signaling processes namely lipolysis signaling (which provides energy-rich equivalents) and autophagy signaling (which is a natural destructive mechanism that disassembles dysfunctional cellular components).

Regarding cold hydrotherapy $(\mathrm{CH})$ naturopathic treatment modality, for many years, a hypothesis of impact of cold water immersion preventing the occurrence of a wide variety of diseases has been elaborated [18]. The $\mathrm{CH}$ is an easy way to boost two of the most powerful natural antioxidant enzymes manufactured by human body, namely glutathione and superoxide dismutase (SOD) which play an essential role in nuclear function preservation and cell survival under oxidative stress [19]. The first enzyme plays a multiple protective roles in cells, including DNA synthesis and repair, cancerous cells metabolism and immune system stimulating. Glutathione antioxidant is a very simple molecule composed by three anemic acids (cysteine, glycine and glutamine) and produced naturally in all the time into human body. However, there are many internal and external factors that contributing together in decreasing its level, including the old age, eating habit, pollution of the surrounding environment, virus infections and ionizing radiations. In the liver, enzymes such as glutathione peroxidase act as catalysts facilitating reactions that render toxins less harmful [20]. Whereas, the second enzyme is responsible for disarming the most dangerous free radicals that may produced by ionizing radiations. Some recent literature describes the effect of $\mathrm{CH}$ on SOD activity, It was found that this activity was higher in volunteers who performing a cold water therapy $[21,22]$. SOD prevents the formation of highly aggressive ROS and convert superoxide to hydrogen peroxide which is then 


\section{Juniper Online Journal of Case Studies}

eliminated by glutathione peroxidase [23]. Mooventhan \& Nivethitha [24] reporting in their paper some of review relevant articles on evidences effects of $\mathrm{CH}$ treatment on various systems of the human body, other papers reported that it enables the stimulation of metabolic system [25]. External use of water doesn't affects not only the exposed. It has immune-stimulating effects, thus it can increased perspiration which may assist in detoxification and it can also improve the circulation of the blood and lymphatics. The $\mathrm{CH}$ of $18{ }^{\circ} \mathrm{C}$ has also a magnitude effect on increasing the number and activities of three kind of lymphocytes namely T, B and Natural killer (NK) cells which is a unique kind of lymphocyte cell that are larger in size than $\mathrm{T}$ and $\mathrm{B}$ lymphocytes and play critical roles in tumor immune surveillance [26]. Since they have the potential to attack many types virus-infected cells, the NK cells kill the disease cells thereby emitting the perforin and granzyme proteins. CE may also assists in increasing of activity and level of neutrophils [27], which are the most plentiful of all white blood cells and play a key role in the innate immune system.

\section{Consequences of the Hypothesis and Discussion}

The present hypothesis can be tested on a number of voluntary patients which are the subject of radiotherapy treatment. Thought this paper we have detailed some scientificbased evidence of both Islamic fasting and cold hydrotherapy in many systems of human body in particular, the immune and metabolic systems. Knowing that these two natural treatment arms seem to be unlikely to cause major clinical problems, a clinical application of these two arms for radiotherapy treatment may enhance its effectiveness.

The scientific evidence-based effects of the two naturopathic treatment discussed in this paper are well documented. However there is a fatal lack of evidences for the mechanism on how they can carried out these effects; this is one of their limitations, and further practical researches should be performed for studying theses effects in cancer patients, decoding the invoked mechanisms and given the relevance and importance of the present hypothesis.

\section{References}

1. Bragazzi NL, Briki W, Khabbache H, Rammouz I, Chamari K, et al (2016) Ramadan fasting and patients with cancer: state-of-the-art and future prospects. Front Oncol 6: 27.

2. Safdie FM, Dorff T, Quinn D, Fontana L, Wei M, et al. (2009) Fasting and cancer treatment in humans: A case series report. Aging (Albany NY) 1(12): 988-1007.

3. Raffaghello L, Safdie F, Bianchi G, Dorff T, Fontana L, et al. (2010) Fasting and differential chemotherapy protection in patients. Cell Cycle 9(22): 4474-4476.

4. Lee C, Safdie FM, Raffaghello L, Wei M, Madia F, et al. (2010) Reduced levels of IGF-I mediate differential protection of normal and cancer cells in response to fasting and improve chemotherapeutic index. Cancer Res 70(4): 1564-1572.

5. de Groot S, Vreeswijk MP, Welters MJ, Gravesteijn G, Boei JJ, et al. (2015)
A pilot study of the effects of short-term fasting on tolerance to (neo) adjuvant chemotherapy in breast cancer patients. BMC Cancer 15: 652 .

6. Safdie F, Brandhorst S, Wei M, Wang W, Lee C, et al. (2012) Fasting enhances the response of glioma to chemo- and radiotherapy. PLoS One 7(9): e44603.

7. Zhang P, Li L, Bao Z, Huang F (2016) Role of BAF60a/BAF60c in chromatin remodeling and hepatic lipid metabolism. Nutr Metab 13: 30.

8. Poplawski MM, Mastaitis JW, Yang XJ, Mobbs CV (2010) Hypothalamic responses to fasting indicate metabolic reprogramming away from glycolysis toward lipid oxidation. Endocrinology 151(11): 5206-5217.

9. Longo VD, Mattson MP (2014) Fasting: molecular mechanisms and clinical applications. Cell Metab 19(2): 181-192.

10. Leiper JB, Molla AM (2003) Effects on health of fluid restriction during fasting in Ramadan. Eur J Clin Nutr 57(Suppl 2): S30-S38.

11. Al-Shafei AI (2014) Ramadan fasting ameliorates arterial pulse pressure and lipid profile, and alleviates oxidative stress in hypertensive patients. Blood Press 23(3): 160-167.

12. Asemi Z, Samimi M, Taghizadeh M, Esmaillzadeh A (2015) Effects of ramadan fasting on glucose homeostasis, lipid profiles, inflammation and oxidative stress in women with polycystic ovary syndrome in kashan, Iran. Arch Iran Med 18(12): 806-810.

13. Denduluri SK, Idowu O, Wang Z, Liao Z, Yan Z, et al. (2015) Insulin-like growth factor (IGF) signaling in tumorigenesis and the development of cancer drug resistance. Genes Dis 2(1): 13-25.

14. Iqbal M, Siddiqui FA, Gupta V, Chattopadhyay S, Gopinath P, et al. (2013) Insulin enhances metabolic capacities of cancer cells by dual regulation of glycolytic enzyme pyruvate kinase M2. Mol Cancer 12: 72.

15. Jakobs HH, Mikula M, Havemeyer A, Strzalkowska A, Chmielak MB, et al. (2014) The N-reductive system composed of mitochondrial amidoxime reducing component (mARC), cytochrome b5 (CYB5B) and cytochrome b5 reductase (CYB5R) is regulated by fasting and high fat diet in mice. PLoS One 9(8): e105371.

16. Dai B, Ruan B, Wu J, Wang J, Shang R, et al. (2014) Insulin-like growth factor binding protein-1 inhibits cancer cell invasion and is associated with poor prognosis in hepatocellular carcinoma. Int J Clin Exp Pathol $7(9): 5645-5654$.

17. Shukla S, Gebregiworgis T, Purohit V, Chaika N, Gunda V, et al. (2014) Metabolic reprogramming induced by ketone bodies diminishes pancreatic cancer cachexia. Cancer Metab 2: 18.

18. Kolettis MT (2003) Winter swimming: healthy or hazardous?. Evidence and hypotheses. Med Hypotheses 61(5-6): 654-656.

19. Hatema E, Berthonauda V, Dardalhond M, Lagniela G, Cornua PB, et al. (2014) Glutathione is essential to preserve nuclear function and cell survival under oxidative stress. Free Radic Biol Med 75(Suppl 1): 103114.

20. Sutkowy P, Woźniak A, Boraczyński T, Kierzenkowska CM, Boraczyński M (2015) Postexercise Impact of Ice-Cold Water Bath on the OxidantAntioxidant Balance in Healthy Men. BioMed Research International 2015(2015): 8 .

21. Wozniak A, Wozniak B, Drewa G, Kierzenkowska CM (2007) The effect of whole-body cryostimulation on the prooxidant-antioxidant balance in blood of elite kayakers after training. Eur J Appl Physiol 101(5): 533537.

22. Afonso V, Champy R, Mitrovic D, Collin P, Lomri A (2007) Reactive oxygen species and superoxide dismutases: role in joint diseases. Joint Bone Spine 74(4): 324-329.

23. Umulis DM, Gurmen NM, Singh P, Fogler HS (2005) A physiologically 
based model for ethanol and acetaldehyde metabolism in human beings. Alcohol 35(1): 3-12.

24. Mooventhan A, Nivethitha L (2014) Scientific evidence-based effects of hydrotherapy on various systems of the body. N Am J Med Sci 6(5): 199-209.

25. Ronda TL, del Alcázar X (2014) The properties of water and their applications for training. J Hum Kinet 44: 237-248.
26. Cheng M, Chen Y, Xiao W, Sun R, Tian Z (2013) NK cell-based immunotherapy for malignant diseases. Cell Mol Immunol 10(3): 230252.

27. Rindfleisch A (2010) Integrative medicine, part 1: incorporating complementary/alternative modalities. In: Rindfleisch A (Ed.), Primary Care Clinics in Office Practice. $\left(1^{\text {st }}\right.$ edn), Elsevier Health Sciences, Amsterdam, Netherlands, p. 227.

This work is licensed under Creative Commons Attribution 4.0 Licens DOI: 10.19080/JOJCS.2017.04.555648 